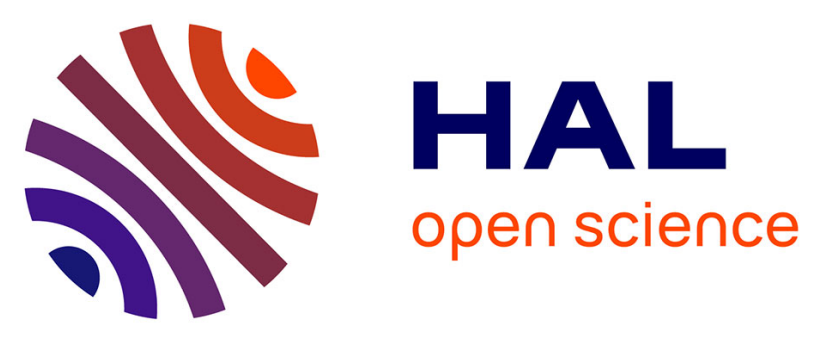

\title{
Spatio-temporal population genetic structure, relative to demographic and ecological characteristics, in the freshwater snail Biomphalaria pfeifferi in Man, western Côte d'Ivoire
}

Yves-Nathan Tian-Bi, Jean-Noël Konan, Abdourahamane Sangaré, Enrique E. Ortega-Abboud, Jürg Utzinger, Eliézer N'goran, Philippe Jarne

\section{To cite this version:}

Yves-Nathan Tian-Bi, Jean-Noël Konan, Abdourahamane Sangaré, Enrique E. Ortega-Abboud, Jürg Utzinger, et al.. Spatio-temporal population genetic structure, relative to demographic and ecological characteristics, in the freshwater snail Biomphalaria pfeifferi in Man, western Côte d'Ivoire. Genetica, 2019, 147 (1), pp.33-45. 10.1007/s10709-018-0049-4 . hal-02366851

\section{HAL Id: hal-02366851 \\ https://hal.science/hal-02366851}

Submitted on 17 Nov 2020

HAL is a multi-disciplinary open access archive for the deposit and dissemination of scientific research documents, whether they are published or not. The documents may come from teaching and research institutions in France or abroad, or from public or private research centers.
L'archive ouverte pluridisciplinaire HAL, est destinée au dépôt et à la diffusion de documents scientifiques de niveau recherche, publiés ou non, émanant des établissements d'enseignement et de recherche français ou étrangers, des laboratoires publics ou privés. 
Tian-Bi et al. GENE-D-17-00317 version September 112018

Yves-Nathan T. Tian-Bi ${ }^{1,2}$, Jean-Noël K. Konan ${ }^{3}$, Abdourahamane Sangaré ${ }^{3}$, Enrique Ortega-Abboud ${ }^{4}$, Jurg Utzinger ${ }^{5}$, Eliézer K. N’Goran²,6 Philippe Jarne ${ }^{4}$

(1)

\section{Spatio-temporal population genetic structure, relative to demographic and ecological} characteristics, in the freshwater snail Biomphalaria pfeifferi, Man, western Côte d'Ivoire

${ }^{1}$ Laboratoire de Génétique, UFR-Biosciences, Université Félix Houphouët-Boigny, 22 BP 1106 Abidjan 22, Côte d'Ivoire

${ }^{2}$ Centre Suisse de Recherches Scientifiques (CSRS) en Côte d'Ivoire, 01 BP 1303 Abidjan 01, Côte d'Ivoire.

${ }^{3}$ Centre National de Recherche Agronomique, Adiopodoumé KM 17, route de Dabou, 01 BP 1740 Abidjan 01, Côte d'Ivoire

${ }^{4}$ Centre d'Ecologie Fonctionnelle et Evolutive, UMR 5175, CNRS - IRD - Université de Montpellier Université Paul Valéry Montpellier - EPHE, 1919 route de Mende, 34293 Montpellier cedex 5, France

${ }^{5}$ Swiss Tropical and Public Health Institute, P.O. Box, CH-4002 Basel, Switzerland

${ }^{6}$ Laboratoire de Zoologie-Biologie Animale, Unité de Recherche et de Formation Parasitologie et Ecologie Parasitaire, UFR Biosciences, Université de Cocody-Abidjan, 22 BP 582 Abidjan 22, Côte d'Ivoire

Corresponding author Tian-Bi T. Yves-Nathan, tianbyth@ yahoo.fr; (+225) 01088960 / 57107394; ORCID 0000-0002-0460-9441 
1 Abstract Combining the analysis of spatial and temporal variation when investigating population structure

2

3 enhances our capacity for unravelling the biotic and abiotic factors responsible for microevolutionary change. This work aims at measuring the spatial and temporal genetic structure of populations of the freshwater snail Biomphalaria pfeifferi (the intermediate host of the trematode Schistosoma mansoni) in relation to the mating system (self-fertilization), demography, parasite prevalence and some ecological parameters. Snail populations were sampled four times in seven human-water contact sites in the district of Man, western Côte d'Ivoire, and their variability was measured at five microsatellite loci. Limited genetic diversity and high selfing rates were observed in the populations studied. We failed to reveal an effect of demographic and ecological parameters on withinpopulation diversity, perhaps as a result of a too small number of populations. A strong spatial genetic differentiation was detected among populations. The temporal differentiation within populations was high in most populations, though lower than the spatial differentiation. All estimates of effective population size were lower than seven suggesting a strong effect of genetic drift. However, it was compensated by high gene flow. The genetic structure within and among populations reflected that observed in other selfing snail species, relying on high selfing rates, low effective population sizes, environmental stochasticity and high gene flow.

Keywords Spatio-temporal structure, demography, parasitic prevalence, gene flow, Biomphalaria pfeifferi

Electronic supplementary material The online version of this article contains supplementary material, which is available to authorized users. 
3 The patterns of genetic variation within and among natural populations depend on several evolutionary forces,

4 including migration, genetic drift and selection (Hartl and Clark 1997; Charlesworth and Charlesworth 2010). Populations of freshwater organisms are generally structured in space and time by marked environmental influences, including for example patchy distribution of habitats and temporal variation in water availability (flooding and droughts). For example, higher gene flow is expected in open (e.g. river) than in closed (e.g. pond) habitats, and genetic drift and extinction should be more common in temporary than in permanent habitats. Empirical studies on population biology and genetics have indeed revealed that the population neutral genetic structure and demographic parameters are affected by habitat characteristics (e.g. Jensen et al. 2005; Lamy et al. 2012; Van Leeuwen et al. 2013; Pauls et al. 2014). Focusing on our group of interest here (freshwater snails), less genetic diversity has for example been observed in closed habitats than in open ones, and in temporary than in permanent habitats (Bousset et al. 2004; Escobar et al. 2008). Of course, biological traits also strongly affect genetic structure, especially the mating system. For example, selfing in freshwater snails leads to a loss of diversity and increased differentiation among populations (Jarne 1995; Charbonnel et al. 2002a, b). Another important aspect is parasitism, since parasites act as extrinsic forces that can shape the genetic structure of their host populations. This may result from a direct demographic effect, since some parasites may cause castration and/or death of infected individuals (Ebert et al. 2004; Blair and Webster 2007), but may also proceed from the connection between host genetic variability and susceptibility / adaptation to parasites. Less diverse and/or less heterozygous populations are generally expected to be less resistant to parasites (Hamilton et al. 1990; Lively 2010). These issues are generally tackled in population genetics based on spatial surveys of genetic variation (Charlesworth and Charlesworth 2010; Rowe et al. 2017). However, temporal approaches provide further information that can deepen our understanding of population dynamics, as indicated by both theoretical (Waples 1989; Hedgecock 1994; Anderson et al. 2010) and empirical (e.g. Kovach et al. 2010; Howells et al. 2013) studies. They provide a direct access to effective population size (Luikart et al. 2010; Hui and Burt 2015), or even to both the effective population size and migration rate (Wang and Whitlock 2003), allowing to evaluate the relative influence of genetic drift and migration. For example, Palm et al. (2003) showed that differences among brown trout populations, previously thought to be genetically differentiated, could be explained solely by temporal variation within populations. Coupled with demographic analyses, this approach has shown its strengths in 
Charbonnel et al. 2002). It even indicates that populations of a snail species occupying a network of ponds work more as a finite island model than as the expected metapopulation model (Lamy et al. 2012).

In such a context, tropical freshwater snails of the Hygrophila group constitute excellent biological models to address the dynamics of population genetic structure in relation to biotic and abiotic factors (Meunier et al. 2001; Charbonnel et al. 2002a, c; Trouvé et al. 2003; Mintsa Nguema et al. 2013). Populations of these snails experience frequent fluctuations in size and dramatic bottlenecks because of seasonal droughts and flooding (Dillon 2000). They have relatively short generation times, from a few weeks to a few months (Brown 1994; Dillon 2000). These hermaphroditic molluscs exhibit either high or low selfing rates (Städler and Jarne 1997; Jarne et al. 2010; Escobar et al. 2011). A consequence of both population demography and selfing is limited neutral variability within populations and fairly large genetic differentiation among populations in selfing species of snails (e.g. Mintsa Nguema et al. 2013). Furthermore, these snails are intermediate hosts for a series of parasitic trematodes, including schistosomes (Brown 1994).

The present study focuses on the freshwater snail Biomphalaria pfeifferi (Planorbidae), the intermediate host of the parasitic trematode Schistosoma mansoni (Schistosomatidae), the agent of human intestinal schistosomiasis in Africa, Madagascar and the Middle-East. The population genetics and biology of this species has been studied in a few work (Charbonnel et al. 2002a, b, c, 2005; Campbell et al. 2010; Mintsa Nguema et al. 2013; Kengne-Fokam et al. 2016). However, populations from Côte d'Ivoire have been little investigated. Tian-Bi et al. (2013), studying the spatial variation of phenotypic traits and at microsatellite markers, confirmed that B. pfeifferi is highly selfing, with limited genetic variability within populations and strong population structure. The phenotypic differentiation was not stronger than the neutral molecular differentiation, suggesting that genetic drift plays a strong role in structuring populations. A temporal approach may help deepening our understanding of the population genetics of this species.

This work aimed at investigating both the spatial and temporal genetic structure of B. pfeifferi populations in relation to their demography and parasitic prevalence. The study was conducted in the Man region (western Côte d'Ivoire) where human populations are significantly affected by infection by S. mansoni. Our analysis is based on seven populations of $B$. pfeifferi separated by a few kilometres that have been sampled four times over a year these sites are those studied by Tian-Bi et al. (2013). The genetic data were analysed in connection with demographic (number of individuals), environmental (e.g. habitat openness) and parasitological (infection by $S$. mansoni) data based on predictions (detailed in the Methods section) relating them. 


\section{Material and methods}

3

\section{Species studied}

Biomphalaria pfeifferi is a freshwater snail distributed over most of Africa, Madagascar and the Middle East (Brown 1994). This highly selfing species (Charbonnel et al. 2005) occupies a variety of water bodies including streams, irrigation channels, ponds and dam lakes (Brown 1994). Populations may experience density variation associated with flooding and drought, leading to bottlenecks and recolonization events (Jarne and Delay 1991; Charbonnel et al. 2002a, b), and to limited neutral variability within populations and strong population structure, even at short geographic distance (Charbonnel et al. 2002a, b, c; Campbell et al. 2010; Mintsa Nguema et al. 2013; Tian-Bi et al. 2013).

\section{Study sites and sampling design}

The study was carried out in the Man region (western Côte d'Ivoire). This mountainous area harbours populations of S. mansoni, the agent of intestinal schistosomiasis (Raso et al. 2005; Assaré et al. 2016). A tropical humid climate prevails in this region, with a rainy season occurring from March to September and a dry season from October to February. The snail populations studied were sampled from seven sites. Four are located in the urban district of Man: Domoraud (DOM), Doyagouiné (DOY), Lycée-Club (LYC), Quartier-Treize (QTT), and three are in the rural area: Blolé (BLO), Nionlé (NIO) and Podiagouiné (POD). Their geographic coordinates are reported in Table 1. Distances between site pairs range from a few hundred of meters to $23 \mathrm{~km}$. Sites were classified according to hydrological characteristics as closed or open for habitat openness, and temporary or permanent for habitat regime (see Bousset et al. 2004; Tian-Bi et al. 2013). The prevalence of S. mansoni in humans in the studied sites during the time period of this work ranged between $21 \%$ and $67 \%$ (Table 1). Snail populations were sampled at four dates. The dry season was sampled at its beginning (October 2004, noted A) and end (January 2005, B), and the rainy season at its beginning (April 2005, C) and middle (June 2005, D). Note that an analysis of spatial genetic structure was reported in Tian-Bi et al. (2013) based on samples from October 2004. During each sampling session, snails were searched and collected over a defined area of each site by the same two persons using a long- 
handle sieve for a period of $10 \mathrm{~min}$. Individuals were brought alive to the laboratory and counted. Samples with less than five individuals were discarded from subsequent analyses.

\section{< Table 1 near here>}

\section{Demography and Schistosoma mansoni prevalence in snail populations}

Demography was analyzed through the number of individuals collected per site and date $(N)$. As sites differed markedly in size, vegetation and water availability, the number of snails collected were compared among samples within sites (i.e. populations), and not among sites. This provided information about the probability of drift and extinction per population (Charbonnel et al. 2002a) which was quantified as the harmonic mean $\left(N_{h}\right)$ and the variance $(\operatorname{Var}(N))$ of $N$ (see Vucetich et al. 1997; Charbonnel et al. 2002a). As the harmonic mean is markedly influenced by low numbers of individuals, low values of $N_{h}$ reflect high probability of extinction (Wright 1938; Charbonnel et al. 2002a). The harmonic mean is not defined in case of null value in a given sample, and we therefore also ran the analyses by replacing null value (no snail detected) by 1 .

Snails were brought alive to the laboratory and reared in batches of 20 individuals (at most) in 21 transparent plastic tanks containing dechlorinated tap water. They were maintained at $23-24^{\circ} \mathrm{C}$ (water temperature) under a 12:12 photoperiod, and fed ad libitum with boiled lettuce. Water was changed at least twice per week. Snails were monitored for parasitic infection by Schistosoma species. To this end, they were observed weekly for the presence of cercariae from day 1 post-sampling until day 45; this allowed detecting infection in snails sampled during the pre-patent period, which is about one month (Pflüger 1976). Snails were checked for cercarial shedding under a binocular microscope after an hour of exposure to artificial light. Indeed, schistosome larvae are generally shed during the day (but see Mouahid et al. 2012), because parasite transmission is insured by human populations. This is likely to be the case in our study area. Schistosomes were identified based on cercariae morphology and displacement (Frandsen and Christensen 1984). Moreover, schistosome egg morphology was used to assess the Schistosoma species to which the shed cercariae belong (see Théron 1986; Mouahid et al. 2012). For this purpose, the schistosome cercariae were collected from naturally infected B. pfeifferi snails and used to infect Swiss white mice. The parasite eggs were then isolated from mice liver and faeces and examined for their morphology under a microscope. The prevalence of $S$. mansoni (IP) was computed per sample, as the total number of infected snails over the total number of individuals tested (Kirkwood 1988). 
3

DNA was extracted from foot tissues and snails were genotyped at five microsatellite loci (Bpf2, Bpf3, Bpf10, Bpf11 and Bpf12) according to Tian-Bi et al. (2013). Due to logistical constraints, the genetic analyses were conducted on samples of 15-20 snails, randomly chosen from initial samples of more than 15 individuals.

\section{Statistical analyses}

(1)

\section{Within-population genetic diversity, parasitic prevalence and demography}

For each temporal sample of snail populations, allelic frequencies were estimated per locus. These estimates are available in Supplementary Table 1 in Supporting Information. The genetic variation within populations was quantified using several standard parameters including the number of polymorphic locus $\left(N_{p l}\right)$, the mean number of alleles per locus $\left(N_{\text {all }}\right)$, the mean observed heterozygosity $\left(H_{O}\right)$ and gene diversity $\left(H_{E}\right)$ (Nei 1987). Genotypic departures from Hardy-Weinberg equilibrium were tested per locus and sample using exact tests, and over all loci using Fisher's method (Rousset 2015). Genotypic disequilibria were tested for all locus pairs within each sample using $G$-based statistics. The unbiased estimator $\hat{f}$ of Wright's inbreeding coefficient $F_{I S}$ was calculated according to Weir and Cockerham (1984). The selfing rate was estimated per population using the relationship $\hat{s}$ $=2 \hat{f} /(1+\hat{f})$ (Pollak 1987). All these genetic estimates and associated significance tests were computed using GENEPOP Version 4.5.1 (Rousset 2015). In populations that were polymorphic at more than a single locus, the selfing rate $\left(\hat{\mathrm{S}}^{\prime}\right)$ was also estimated using the maximum-likelihood multilocus method implemented in RMES (David et al. 2007).

The effects of environmental and demographic stochasticity on genetic diversity $\left(H_{E} ; N_{\text {all }}\right)$ and selfing rate (through $\hat{f}$ ) within populations were tested using a multiple regression analysis in which season, habitat openness, habitat regime, $N_{h}, \operatorname{Var}(N)$ and $S$. mansoni infection prevalence (IP) were used as predicting (independent) variables. Then the effect of each independent variable was tested separately using an ascendant stepwise regression. Lower values of $H_{E}$ and $N_{a l l}$, and higher values of selfing rates are expected during the dry season (due to higher probability of 
drift within populations), in temporary habitats (with higher drift due to regular droughts) and in closed habitats (which are more likely to completely dry out) (Charbonnel et al. 2002b; Bousset et al. 2004). A positive correlation was expected between $N_{h}$ and both $H_{E}$ and $N_{\text {all }}$. Moreover, a negative correlation was expected between the selfing rate and $N_{h}$. Host diversity may be affected by parasites. Indeed, parasites may reduce host population sizes, and therefore their genetic diversity (Lively 2010; Whitehorn et al. 2011), leading here to a negative correlation between IP and diversity $\left(H_{E}\right.$ and $\left.N_{a l l}\right)$. In addition, traits related to fitness, such as the susceptibility to parasites, may be affected by inbreeding (Charlesworth and Willis 2009), generating a positive correlation between IP and $\hat{f}$ and a negative one between IP and $H_{E}$ (Charbonnel et al. 2002a).

The regression analyses were performed using the software STATISTICA version 7.1 (Stat Soft 2005).

\section{Genetic differentiation among populations}

The spatial genetic differentiation was analysed estimating the global $F_{\text {Sт }}$ over all loci (Weir and Cockerham 1984),

over all populations $\left(\hat{\theta}_{g}\right)$ and over all populations sampled at the same date $\left(\hat{\theta}_{g-s p}\right)$. We also computed the global estimator of $F_{S T}$ over all populations sampled within the same season $\left(\hat{\theta}_{S}\right)$, over all populations according to habitat openness $\left(\hat{\theta}_{H O}\right)$, over all populations according to habitat regime $\left(\hat{\theta}_{H R}\right)$. Estimates of spatial differentiation were also computed between population pairs at a given sampling date $\left(\hat{\theta}_{2-s p}\right)$. Two additional methods were used to assess the spatial differentiation among populations. (i) For each of the three sampling dates A, B and C, isolation by distance was tested using a Mantel-like test on the relationship between genetic distance estimated by $F_{S T} /\left(1-F_{S T}\right)$ and the logarithm of geographic distance (Rousset 2015). This test was not conducted with sample D (June 2005), because only two snail samples were obtained at this date. (ii) Assignment and exclusion methods were applied to identify immigrants and their origin (Cornuet et al. 1999) within populations for the same sampling date. Individuals were excluded when their probability of belonging to a population was below 0.05 . Excluded individuals were reassigned to the population for which their probability of belonging is the highest. Reassignment was done only for probabilities higher than 0.10 (Cornuet et al. 1999). The assignment probability was based on Cavalli-Sforza's chord distance (Cavalli-Sforza and Edwards 1967). A GLM was used to test the effects of season and habitat on exclusion/reassignment rates. More exclusion (i.e. migration) was expected in the rainy season and in open habitats. 
1 Temporal genetic differentiation $\left(\hat{\theta}_{t p}\right)$ was analysed per population by estimating the temporal differentiation both over all sampling dates and between two successive samples. The distributions of genetic differentiation between population pairs for a given sampling date $\left(\hat{\theta}_{2-s p}\right)$ and temporal genetic differentiation between two successive samples for a given population were compared using Wilcoxon test. High temporal differentiation could indicate a substantial decrease of population sizes or extinction followed by immigration or recolonization within the same population over time, resulting in substantial genetic drift (Charbonnel et al. 2002b; Lamy et al. 2012). All estimates of genetic differentiation and their associated $P$-values were computed using GENEPOP Version 4.5.1 (Rousset 2015). Tests of genetic variation conducted with the GENEPOP package were based on Markov chain procedure (parameters: 1000000 for dememorisation, 1000 batches and 10000 iterations per batch).

Temporal differentiation was also used to jointly estimate the effective population size $\left(N_{\mathrm{e}}\right)$ and migration rate $(m)$ based either on two successive samples, or over all samples for a given population, using the likelihood method of Wang and Whitlock (2003). Samples separated by two to three months were assumed to bridge one generation (see Charbonnel et al. 2002b; Tian-Bi et al. 2008, 2013). The samples of October 2004 (A) were considered as generation zero, and those of January 2005 (B), April 2005 (C) and June 2005 (D) as generation 1, 2, and 3 respectively. The method assumes an infinitely large source population providing immigrants to the focal population in which $N_{\mathrm{e}}$ and $m$ are estimated. The maximum $N_{\mathrm{e}}$ was set at 1000 and the source population was constituted from all other samples except that of the focal population. $N_{\mathrm{e}}$ and $m$, and their $95 \%$ confidence intervals, were estimated using the program MLNE Version 1.0 (Wang and Whitlock 2003). The relationships between temporal $F_{S T}$, and both $N_{\mathrm{e}}$ and $m$ were assessed using multiple regressions.

Control for multiple testing was performed based on the false discovery rate (FDR) method of Benjamini and Hochberg (1995).

Spatial and temporal differentiation were further analysed using the sNMF (Bayesian) approach to population structure developed by Frichot et al. (2014). This method is akin to methods reconstituting population clusters based on ancestry coefficients such as that implemented in STRUCTURE (Pritchard et al. 2000), but is as efficient in terms of inference of cluster number and runs much faster. Importantly, it is not sensible to strong inbreeding, as shown by Frichot et al. (2014) in their analysis of the highly selfing plant Arabidopsis thaliana. The sNMF approach was performed using the R package LEA (Frichot and François 2015) was run using all data with a target number of clusters varying from 1 to 20 and the default regularization parameter of 10 . We run further simulations considering the October 2004, January 2005 and April 2005 samples apart, with 1 to 17 clusters (simulations 
stalled at higher value due to the lower amount of individuals). We also ran simulations using InStruct software (Gao et al. 2007) which is based on the same approach and got essentially similar results (not shown).

\section{Results}

\section{Demography, parasitic prevalence and variability within populations}

Over the seven studied populations surveyed between October 2004 and June 2005, no snails were found in five cases, one in January 2005 (QTT-B) and four in June 2005 (DOM-D, DOY-D, QTT-D and POD-D). A single individual was collected in NIO-D (June 2005). We thus obtained 22 samples including 1020 snails (mean per sample: 36.43; s.d.: 37.08) for the genetic analyses. In most populations, the highest $N$ was detected during the dry season (Table 2). We observed strong variation in both $N_{h}$ (harmonic mean of $\left.N\right)$ and $\operatorname{Var}(N)(\operatorname{variance}$ of $N)$. $N_{h}$ varied from 1.97 in QTT to 30.92 in LYC and $\operatorname{Var}(N)$ from 126.33 in POD to 2900.92 in LYC.

Snails were found infected by schistosomes at least once in six of the seven populations studied. Identification based on egg morphology showed that all the screened eggs exhibit the S. mansoni morphology. The mean prevalence of $S$. mansoni varied from 0.00 in NIO to 0.23 in DOY. The highest prevalence was observed during the dry season (e.g. 0.68 in DOY-A; Table 2).

\section{< Table 2 near here $>$}

The genetic variation within populations was low (Table 2). Considering the loci separately, all snail samples were fixed for one allele at one locus at least and monomorphism was observed in 60 locus-sample situations out of 110 (see Online Resource 1). The number of polymorphic loci per sample ranged from 1 to 4 , and the mean per population from 1.67 to 3.33 (Table 2). The mean number of alleles per locus $\left(N_{\text {all }}\right)$ ranged from 1.20 to 2.20 , and the mean per population from 1.40 to 1.67 . Gene diversity $\left(H_{E}\right)$ per sample varied from 0.02 to 0.24 , and its mean value per population from 0.04 to 0.16 . No heterozygote was detected in six samples and the highest observed heterozygosity was detected in LYC-D $\left(H_{O}=0.13\right.$; Table 2). Overall, similar values of the standard genetic parameters were detected over time within each of the seven populations studied (chi-square tests lead to $P$-values $>0.05$ within all populations). The test of Hardy-Weinberg equilibrium (HWE) at each locus per snail sample was possible in 50 cases only (due to monomorphism), and significant departures from HWE were detected in 23 
2 samples out of 22. Except for two samples (LYC-D and NIO-B), the estimates of $F_{\text {IS }}(\hat{f})$ were all higher than

$3 \quad 0.75$. The selfing rate $(\hat{s})$ derived from $\hat{f}$ thus ranged between 0.57 and 1 , with the lower selfing rate observed in LYC-D and pure selfing detected in six samples (DOM-A, LYC-A, POD-A, DOY-B, QTT-C and BLO-C). The

5

samples after FDR correction (Supplementary Table 1). Multilocus departure from HWE was significant for 14 selfing rate $\hat{s}^{\prime}$ based on RMES ranged between 0.76 and 0.98 (Table 2). Tests of genotypic disequilibrium were performed within populations for 56 locus pairs only (out of 220 possible pairs), and significant disequilibria were found for Bpf10-Bpf11 and Bpf3-Bpf11 in DOY-A $(P=0.008)$ and DOY-C $(P=0.001)$, respectively. This is no more than what is expected by chance at the 5\% significance level. After adjustment of $p$-values following the procedure of Benjamini and Hochberg (1995), none of the demographic and ecological parameters was correlated with those of within-population genetic diversity (Table 3).

\section{< Table 3 near here >}

\section{Among-population differentiation}

The global estimate $\left(\hat{\theta}_{\mathrm{g}}\right)$ of $F_{\mathrm{ST}}$ over all the 22 temporal snail samples was 0.67 . The $F_{\mathrm{ST}}$ estimates over all populations sampled at the same date were above 0.60 for the first three dates and equal to 0.46 for sample D.

Estimates of differentiation over all populations sampled during the same season $\left(\hat{\theta}_{\mathrm{S}}\right)$ were 0.69 and 0.65 for the dry season and for the rainy season, respectively. $F_{\mathrm{ST}}$ estimates over all populations from the same type of habitat were $0.66,0.59,0.66$ and 0.68 for open, closed, temporary and permanent habitats, respectively (Online Resource 2). The pairwise $F_{\mathrm{ST}}$ estimates $\left(\hat{\theta}_{2-\mathrm{sp}}\right)$ ranged between 0.07 and 0.93 in October 2005 , between -0.005 and 0.81 in January 2005, and between 0.003 and 0.93 in April 2005 as indicated in Online Resource 3 (OR3A, OR3B,

OR3C). The sole pairwise $F_{\text {ST }}$ estimates ( $\hat{\theta}_{2 \text {-sp }}$ ) of June 2005 was 0.46 . Most estimates were significantly different from zero $(P<0.001)$.

No significant isolation by distance was detected for each of the three sampling dates (A, B, C) tested (all $P$ > 0.05). Assignment analyses indicated that the probabilities of assigning individuals to the population in which they were sampled was high for each sampling date, though low rates of assignment were observed in April 2005 (Fig. 
1). Individuals of other origin were detected within 20 out of the 22 samples. The percentage of excluded individuals ranged between 0 (in DOY-A and NIO-A) to 95\% (in QTT-A and QTT-C). Most of the excluded individuals were reassigned to populations geographically close to populations in which they were sampled. The exclusion percentage was affected by habitat openness only, with higher values observed in closed habitats (mean, open habitats $=20.38 \% /$ closed habitats $=50.96 \%$, GLM,$P=0.012)$.

$F_{\mathrm{ST}}$ estimates over all sampling dates for the same population ranged between -0.02 and 0.67 (Table 4). These estimates differed all from zero $(P<0.001)$, except for the values in the POD and QTT populations. All values of genetic differentiation between two successive samples for the same population differed significantly from zero $(P<0.001$; Table 4), except in the POD population. Estimates between successive samples were also significantly different from 0 in 10 situations out of 14 (Table 4). POD again showed great temporal stability. The mean spatial differentiation was significantly higher than the mean temporal differentiation (Wilcoxon test, $\mathrm{z}=2.33, P=0.020$ ). Estimates of effective population size $\left(N_{\mathrm{e}}\right)$ between successive samples were all different from zero, though below 7 in all cases, ranging between 2 and 6.4. Likewise, the estimates of migration rate per generation $(m)$ were all significantly different from zero and the values varied from $8 \cdot 10^{-5}$ to 1 (Table 4). Estimates over all samples ranged between 2.5 and 4.4 for $N_{\mathrm{e}}$, and from 0.0002 to 0.94 for $m$. Temporal $F_{S T}$ was negatively associated with $N_{\mathrm{e}}$ and positively correlated with $m$ (whole model: $F_{3,18}=16.05$; error mean square $=0.02 ; P<0.0001$ ).

The Bayesian analysis using sNMF returned six groups when considering all populations at once (Online Resource 4 and 5). However, the six groups do not correspond to the seven populations. The sample clustering is consistent with the pairwise $F_{S T}$ values, and somewhat with the geographical distances; for example, DOY, QTT et LYC are closely related, although this is not fully stable in time, while DOM is rather apart as a mix of different clusters. NIO (late samples) and POD are clustered in a single group. Seven clusters were returned by Instruct (not shown). A comparison with results from sNMF with the same number of clusters indicate that we retrieved similar grouping (e.g., LYC and QTT are related; DOM is apart) with some variation indicative of a labile spatio-temporal genetic structure. A separate sNMF analysis of each sampling time retained four to five clusters (not shown) with again limited stability of clusters in time. This is consistent with the results above with allelic frequency rapidly changing through time.

\section{Discussion}


The current study addresses the spatial and temporal distribution of neutral molecular variation of Biomphalaria pfeifferi populations in connection with demographical, ecological and parasitological parameters. We discuss below successively what the analysis of within- and among population structure brings to our understanding of the functioning of these populations. Given the limited number of individuals and populations considered, our conclusions should of course be considered with caution.

\section{Demography, parasite prevalence and their influence on within-population genetic diversity} 8

Our previous study (Tian-Bi et al. 2013) conducted on the first seven samples of B. pfeifferi snails, collected in October 2004 and designated here as sample A, revealed a limited genetic diversity within populations. This pattern was confirmed with the three other samples (B, C and D), with fixation of an allele at least at one locus in the 22 samples and low values of standard genetic parameters $\left(N_{p l}, N_{a l l}, H_{O}\right.$ and $\left.H_{E}\right)$. This low genetic diversity results in part from the mating system. Our analysis indeed confirms that B. pfeifferi is a preferential selfer, as shown for example by Charbonnel et al. (2005) in populations from Madagascar. Selfing decreases the effective population size, and therefore the within-population variation (Jarne 1995; Ingvarsson 2002). A further process potentially leading to low variation is limited population size. This is often assumed in population genetics studies, but more rarely followed in time based on genetic analyses. We here observed large temporal fluctuation in the number of snails collected per site - the largest values were obtained during the dry season when site size is shrinking and populations contract on limited areas and the smallest in the middle of the rainy season when sites exhibit their largest size and individuals are dispersed by water flows, resulting in a large $\operatorname{Var}(N)$ and small $N_{h}$ in most sites with $N_{h}<4$ in most samples (note though that $N_{h}$ was driven down by demographic extinction in some samples). This confirms the demographic pattern observed in freshwater snails, both in general (Dillon 2000) and in planorbid snails in Africa and Madagascar, including B. pfeifferi (Loreau and Baluku 1987; Woolhouse 1992; Brown 1994; Charbonnel et al. 2002a). The effective size, as estimated from the method of Wang and Whitlock (2003), was accordingly small. The effective size is indeed strongly influenced by low densities (Wright 1938; Kalinowski and Waples 2002). Our data suggest that at least four of the studied populations went through strong bottlenecks, but were rapidly recolonized. Extinction / colonization processes tend to depress variation within populations (Ingvarsson 2002). This was also shown in populations of vertebrates such as brown trout (Salmo trutta: Salmonidae) (Jensen et al. 2005). 
All the snails screened were infected with $S$. mansoni-like parasite (our method does not allow to ascertain species status). Such an observation seems consistent with the prevalence of S. mansoni infection in humans in Man, where up to $67 \%$ persons suffer from intestinal schistosomiasis. According to OMS (2004), this rate corresponds to a high prevalence of S. mansoni, indicating a strong presence (or pressure) of this parasite in both human and snail hosts in the area and during the time period of this study. At the same time, the values of S. mansoni infection prevalence in snails were very low in this work as previously shown by numerous field studies on schistosome infections (Anderson and May 1979; Hamberger et al. 1998; Sire et al. 1999; Charbonnel et al. 2002a; De Kock et al. 2004). This may be explained by the low probability of an encounter between snails and schistosomes (Mitta et al. 2017). High prevalence of schistosomiasis in final hosts is often observed in conjunction with low infection rates in snails (see e.g., De Kock et al. 2004 in B.pfeifferi), but infection rates in these latter may increase when site size is shrinking at the end of the dry season (Woolhouse and Chandiwana, 1989). Parasites may exert a pressure on host survival, further depressing sizes of host populations (Lively 2010; Whitehorn et al. 2011) and contributing here to lower genetic diversity. This should be investigated in more details.

We did not detect an effect of demographic and ecological parameters on within-population diversity as found in other studies (e.g. Lamy et al. 2012). This may be due to the limited number of populations (7) and individuals (421) considered here compared with previous studies in B. pfeifferi (Charbonnel et al. 2002a,b; Campbell et al. 2010; Mintsa Nguema et al. 2013) where up to 30 populations and above 30 individuals per population were analysed at up to 18 microsatellite markers. The limited number of loci (5) is probably of lower importance. Moreover, at this small spatial scale, similar ecological factors might have played as homogenizing factors among genetically and geographically close populations, as observed in our previous study on the first seven snail samples with no difference among populations for several fecundity traits (Tian-Bi et al. 2013). Although we found no significant effect of environmental parameters on genetic diversity, a trend towards higher mean gene diversity $\left(H_{E}\right)$ in open habitats seemed to be observed (see Table 3). This is consistent with previous studies in freshwater snails when contrasting open and closed sites (Charbonnel et al. 2002c; Bousset et al. 2004; Escobar et al. 2008) or more or less connective sites (Lamy et al. 2012). Indeed, migration and colonization should maintain larger effective population size (i.e. more variation) in open habitats Bousset et al. 2004; Escobar et al. 2008).

\section{Among-population genetic differentiation}


A strong global genetic differentiation (0.67) was observed among all the 22 temporal snail samples. This estimate is slightly higher than that obtained (0.58) at a similar scale over 19 populations from the Ihosy region in Madagascar (Charbonnel et al. 2002b). More generally, empirical studies show that the genetic differentiation is extremely high in selfing species, whether in plants (e.g. Porcher et al. 2006) or in animals (Viard et al. 1997; Charbonnel et al. 2002a, b, c). Whatever the spatial partitioning considered (i.e. among populations sampled at the same date, during the same season and from the same habitat type), the global estimates of $F_{\mathrm{ST}}$ were above 0.59 to the exception of sample D (which however included a lower number of samples). This is consistent with the prediction derived from the theory of structured populations / metapopulations (Jarne 1995; Ingvarsson 2002): differentiation should increase with the selfing rate, because of both decreased effective population size and decreased effective migration rate (when migration occurs in the diploid state). This can simply be envisioned under the island model: the equilibrium value of $F_{\mathrm{ST}}$ is the inverse of $1+4 \mathrm{Nm}$ in outcrossing populations (see e.g. Whitlock and McCauley 1999) and therefore of $1+N m$ in selfing populations, with $N$ the effective population size and $m$ the migration rate, leading to much higher differentiation. The $\mathrm{Nm}$ product can here be derived from the analysis based on Wang and Whitlock's (2003) method. From Table 4, we can infer that $\mathrm{Nm}$ is generally (slightly) greater than one, consistent with $F_{\mathrm{ST}}$ values higher than 0.5 (assuming an island model). More interestingly, although the $F_{\text {ST }}$ estimates taken at face value are pretty high, migration is strong enough to maintain a continuous input of genetic variation and to depress the influence of genetic drift due to small size and bottlenecks.

Our study indicates that the temporal differentiation within populations can be extremely high, almost as high as the spatial differentiation in five out of seven populations. This is somewhat unexpected: in previous studies conducted in snail species, the temporal differentiation is generally much lower than the spatial differentiation in outcrossing species ( $c a$. an order of magnitude; e.g. Lamy et al. 2012). In selfing species for which such an estimate is available, the temporal / spatial ratio of differentiation was found to be of the order of two (Viard et al. 1997; Charbonnel et al. 2002c). This again pleads for a very dynamical system in which the marked demographical variation that should lead to very limited variation is counter-acted by efficient migration. The estimates of migration rate were indeed pretty high, leading as mentioned above to $\mathrm{Nm}$ values above one in general. A note of caution should be introduced here: in the much more detailed and extensive analysis of Lamy et al. (2012) conducted in Lesser Antilles populations of the outcrossing snail Drepanotrema depressissimum, there was no relationship between estimated population size based on genetic markers (microsatellites) and demographic results; demographic extinction can indeed have absolutely no influence on genetic variation. In addition to efficient migration in this system, this is also due to the fact that this species may survive through dry periods, 
apparently hiding in dry mud. The probability of population persistence is indeed higher in sites that dry out than in sites that remain wet (Lamy et al. 2013). The aestivation ability of B. pfeifferi has not been evaluated experimentally, but most tropical freshwater pulmonates can aestivate for some time (Brown 1994). If true, this should decrease the temporal estimates of genetic differentiation, contrary to what has been observed here.

The negative correlation between temporal $F_{S T}$ and $N_{\mathrm{e}}$ is to some extent similar to some results found by Lamy et al. (2012). It suggests the occurrence of bottlenecks between successive temporal samples. This contrasts with the positive correlation between temporal $F_{S T}$ and $m$. Indeed, migration tends to genetically homogenise populations, leading to the reduction of value of $F_{S T}$. In this study, a substantial amount of migration was observed among populations.

The results from sNMF analysis of temporal genetic structure of populations are to some extent consistent with those on temporal differentiation $\left(F_{S T}\right)$, estimates of $N$ and $m$. These latter also corroborate the results from the assignment method. The proportion of individuals that were re-assigned to their population of origin is rather high, and most of the excluded individuals (77.4\%) were reassigned to geographically close populations, a much higher value than in the Malagasy populations of Charbonnel et al. (2002c), but in line with the results of Lamy et al. (2012) in $D$. depressissimum. This is consistent with the isolation by distance patterns, i.e. the increase of pairwise $F_{S T}$ with geographic distance. Note that $22.6 \%$ of the excluded individuals were not reassigned to any of the sampled populations, indicating that their population of origin were not sampled. This is not surprising given the limited number of populations sampled, and calls for more extensive sampling in the future. Surprisingly, the percentage of exclusion was higher in closed than in open habitats. This is inconsistent with the prediction of higher immigration expected in open habitat, but not with the possibility that populations of $B$. pfeifferi might survive very well through dry periods. Another explanation is that most of the closed habitats surveyed are manmade (e.g. POD is a fish pond with and QTT is an irrigation well), which can be filled with water from elsewhere, therefore allowing more immigration than expected for closed sites.

The analysis based on the sNMF approach allowed us to consider all samples at once, and produced results which are consistent with the comparison based on pairwise $F_{S T}$. Six clusters were detected, but they do not correspond to populations with some populations associated at one time point and not at another, suggesting significant temporal variation within population. Some populations are however more closely related, and one remains somewhat apart. On the whole, all the results on population genetic structure are consistent with a system working as a metapopulation from a demographical point of view, with frequent extinction and colonization events, as observed in previous work conducted in this species (Charbonnel et al. 2002a; Gow et al. 2007; Campbell et al. 
2010; Mintsa Nguema et al. 2013). However, the spatial and temporal differentiation, even if strong considering the spatial scale at which the study was conducted and affected by low effective population size, is maintained below that expected under fixation of alleles in all populations / loci by migration. Another possibility is that individuals are able to aestivate in dried-out sites, maintaining more variation than expected in a metapopulation. This is what has been suggested by Lamy et al. (2012) in another snail species. However, a much more detailed analysis would be required to be more conclusive on whether our study system is a metapopulation or a structured population, including genetic data, long-term demographical survey of populations and ecological follow-up of sites (see Lamy et al. 2012).

Acknowledgments We thank two reviewers for interesting comments. This work received financial support from the Swiss Development Cooperation (SDC) allocated to the Centre Suisse de Recherches Scientifiques (CSRS) via a project entitled "Contribution to the process of national reconciliation in Côte d'Ivoire" (AVS). We are grateful to the Swiss Tropical and Public Health Institute (Swiss TPH) for having entirely supported the purchase of all the genetic analysis materials. We thank the Centre National de Recherche Agronomique (CNRA) for having allowed snail genotyping in the Laboratoire Central de Biotechnologie (LCB). We are also grateful to Rodolphe Dieugbé from ODAFEM-Man for his assistance during snail sampling.

\section{Compliance with ethical standards}

Conflict of Interest Author Yves-Nathan T. Tian-Bi declares that he has no conflict of interest. Author Jean-Noël K. Konan declares that he has no conflict of interest. Author Abdourahamane Sangaré declares that he has no conflict of interest. Author Enrique Ortega-Abboud declares that he has no conflict of interest. Author Jurg Utzinger declares that he has no conflict of interest. Author Eliézer K. N'Goran declares that he has no conflict of interest. Author Philippe Jarne declares that he has no conflict of interest.

\section{References}

Anderson CD, Epperson BK, Fortin MJ et al (2010) Considering spatial and temporal scale in landscape-genetic studies of gene flow. Mol Ecol 19:3565-3575 
Anderson RM, May RM (1979) Prevalence of schistosome infections within molluscan populations: observed patterns and theoretical predictions. Parasitology 79:63-94

Assaré RK, Tian-Bi Y-NT, Yao PK et al (2016) Sustaining control of Schistosomiasis mansoni in western Côte d'Ivoire: results from a SCORE study, one year after initial praziquantel administration. PLoS Negl Trop Dis 10:e0004329

Benjamini Y, Hochberg Y (1995) Controlling the false discovery rate: a practical and powerful approach to multiple testing. J R Stat Soc Series B Stat Methodol 57:289-300

Blair L, Webster JP (2007) Dose-dependent schistosome-induced mortality and morbidity risk elevates host reproductive effort. J Evol Biol 20:54-61

Bousset L, Henry P-Y, Sourrouille P, Jarne P (2004) Population biology of the invasive freshwater snail Physa acuta approached through genetic markers, ecological characterization and demography. Mol Ecol 13:20232036

Brown D (1994) Freshwater snails of Africa and their medical importance, 2nd edn. Taylor and Francis Ltd, London

Campbell G, Noble LR, Rollinson D et al (2010) Low genetic diversity in a snail intermediate host (Biomphalaria pfeifferi Krass, 1848) and schistosomiasis transmission in the Senegal River Basin. Mol Ecol, 19:241-256

Cavalli-Sforza LL, Edwards AWF (1967) Phylogenetic analysis: models and estimation procedures. Am J Hum Genet 19:233-257

Charbonnel N, Angers B, Rasatavonjizay R et al (2002a) Evolutionary aspects of the metapopulation dynamics of Biomphalaria pfeifferi, the intermediate host of Schistosoma mansoni. J Evol Biol 15:248-261

Charbonnel N, Angers B, Rasatavonjizay R et al (2002b) The influence of mating system, demography, parasites and colonisation on the population structure of Biomphalaria pfeifferi in Madgascar. Mol Ecol 11:2213-2228

Charbonnel N, Quesnoit M, Razatavonjizay R et al (2002c) A spatial and temporal approach to microevolutionary forces affecting population biology in the freshwater snail Biomphalaria pfeifferi. Am Nat 160:741-755

Charbonnel N, Rasatavonjizay R, Sellin E et al (2005) The influence of genetic factors and population dynamics on the mating system of the hermaphroditic snail Biomphalaria pfeifferi. Oikos 108:283-296

Charlesworth D, Willis JH (2009) The genetics of inbreeding depression. Nat Rev Genet 10:783-796

Charlesworth B, Charlesworth D (2010) Elements of evolutionary genetics. Roberts \& Co. Greenwood Village, $\mathrm{CO}$ 
Cornuet J-M, Piry S, Luikart G et al (1999) New methods employing multilocus genotypes to select or exclude populations as origins of individuals. Genetics 153:1989-2000

David P, Pujol B, Viard F et al (2007) Reliable selfing rate estimates from imperfect population genetic data. Mol Ecol 16:2474-2487

De Kock KN, Wolmarans CT, Bornman M (2004) Distribution and habitats of Biomphalaria pfeifferi, snail intermediate host of Schistosoma mansoni, in South Africa. Water SA, 30:29-36

Dillon RT (2000) The Ecology of Freshwater Molluscs. Cambridge University Press

Ebert D, Carius HJ, Little T, Decaestecker E (2004) The evolution of virulence when parasites cause host castration and gigantism. Am Nat 164:S19-S32

Escobar JS, Nicot A, David P (2008) The difference sources of variation in inbreeding depression, heterosis and outbreeding depression in a metapopulation of Physa acuta. Genetics 180:1593-1608

Escobar JS, Auld JR, Correa AC et al (2011) Patterns of mating-system evolution in hermaphroditic animals: Correlations among selfing rate, inbreeding depression and delayed selfing: patterns of mating-system evolution in hermaphroditic animals. Evolution 65:1233-1253

Frandsen F, Christensen NØ (1984) An introduction guide to the identification of cercariae from African freshwater snail with special reference to cercariea of trematode species of medical and veterinary importance. Acta Trop 41:181-202

Frichot E, François O (2015) LEA: an R package for landscape and ecological association studies. Methods in Ecology and Evolution 6:925-929

Frichot E, Mathieu F, Trouillon T, Bouchard G, François O (2014) Fast and efficient estimation of individual ancestry coefficients. Genetics 196:973-983

Gao H, Williamson S, Bustamante CD (2007) An MCMC approach for joint inference of population structure and inbreeding rates from multi-locus genotype data. Genetics (online)

Gow JL, Noble LR, Rollinson D et al (2007) Contrasting temporal dynamics and spatial patterns of population genetic structure correlate with differences in demography and habitat between two closely related African freshwater snails. Biol J Linn Soc Lond 90:747-760

Hamilton WD, Axelrod R, Tanese R (1990) Sexual reproduction as an adaptation to resist parasites (a review). Proc Natl Acad Sci USA 87:3566-3573

Hartl DL, Clark AG (1997) Principles of Population Genetics, 3rd edn. Sinauer Associates, Sunderland, Massachusetts 
Hedgecock D (1994) Does variance in reproductive success limit effective population sizes of marine organisms? In Beaumont AR (ed) Genetics and the Evolution of Aquatic Organisms. Chapman and Hall, London, pp 122134

Howells EJ, Willis BL, Bay LK, Oppen MJ (2013) Spatial and temporal genetic structure of Symbiodinium populations within a common reef-building coral on the great barrier reef. Mol Ecol 22:3693-3708

Hui TYJ, Burt A (2015) Estimating effective population size from temporally spaced samples with a novel, efficient maximum-likelihood algorithm. Genetics 200:285-293

Ingvarsson PK (2002) A metapopulation perspective on genetic diversity and differentiation in partially selffertilizing plants. Evolution 56:2368-2373

Jarne P, Delay B (1991) Population genetics of freshwater snails. Trends Ecol Evol 6:383-386

Jarne P (1995) Mating system, bottlenecks and genetic polymorphism in hermaphroditic animals. Genet Res 65:193-207

Jarne P, Pointier J-P, David P, Koene JM (2010) Basommatophoran Gastropods. In Córdoba-Aguilar and JL Leonard (eds A) The Evolution of Primary Sexual Characters in Animals. Oxford University Press, Oxford, pp 173-196

Jensen LF, Hansen MM, Carlsson J et al (2005) Spatial and temporal genetic differentiation and effective population size of brown trout (Salmo trutta, L.) in small Danish rivers. Conserv Genet 6:615-621

Kalinowski ST, Waples RS (2002) Relationship of effective to census size in fluctuating populations. Conserv Biol 16:129-136

Kovach AI, Breton TS, Berlinsky DL et al (2010) Fine-scale spatial and temporal genetic structure of Atlantic cod off the Atlantic coast of the USA. Mar Ecol Prog Ser 410:177-195

Kengne-Fokam AC, Nana-Djeunga HC, Djuikwo-Teukeng FF, Njiokou F (2016) Analysis of mating system, fecundity, hatching and survival rates in two Schistosoma mansoni intermediate hosts (Biomphalaria pfeifferi and Biomphalaria camerunensis) in Cameroon. Parasit Vectors 9:10. https://doi.org/10.1186/s13071-015$1285-4$

Kirkwood BR (1988) Essentials of medical statistics. Blackwell Scientific Publications

Lamy T, Pointier J-P, Jarne P, David P (2012) Testing metapopulation dynamics using genetic, demographic and ecological data. Mol Ecol 21:1394-1410

Lamy T, Gimenez O, Pointier J-P et al (2013) Metapopulation dynamics of species with cryptic life stages. Am Nat 181:479-491 
Lively CM (2010) A review of Red Queen models for the persistence of obligate sexual reproduction. J Hered 101:S13-S20

Loreau M, Baluku B (1987) Growth and demography of populations of Biomphalaria pfeifferi (Gastropoda, Planorbidae) in the laboratory. J Molluscan Stud 53:171-177

Luikart G, Ryman N, Tallmon DA et al (2010) Estimation of census and effective population sizes: the increasing usefulness of DNA-based approaches. Conserv Genet 11:355-373

Meunier C, Tirard C, Hurtrez-Boussès S et al (2001) Lack of molluscan host diversity and the transmission of an emerging parasitic disease in Bolivia. Mol Ecol 10:1333-1340

Mintsa Nguema RM, Langand J, Galinier R et al (2013) Genetic diversity, fixation and differentiation of the freshwater snail Biomphalaria pfeifferi (Gastropoda, Planorbidae) in arid lands. Genetica 141:171-184

Mitta G, Gourbal B, Grunau C, Knight M, Bridger JM, Théron A (2017) The compatibility between Biomphalaria glabrata snails and Schistosoma mansoni: an increasingly complex puzzle. Adv Parasitol 97:111-145

Mouahid G, Idris MA, Verneau O, Théron A, Shaban MM, Moné H (2012) A new chronotype of Schistosoma mansoni: adaptive significance. Trop Med Int Health 17:727-732

Nei M (1987) Molecular Evolutionary Genetics. Columbia University Press, New York

OMS - Organisation Mondiale de la santé (2004) Agir contre les vers. Janvier 2004 numéro 4

Pauls SU, Alp M, Bálint M et al (2014) Integrating molecular tools into freshwater ecology: developments and opportunities. Freshw Biol 59:1559-1576

Palm S, Dannewitz J, Järvi T et al (2003) Lack of molecular genetic divergence between sea-ranched and wild sea trout (Salmo trutta). Mol Ecol 12:2057-2071

Pflüger W (1976) Ecological studies in Madagascar of Biomphalaria pfeifferi, intermediate host of Schistosoma mansoni. 1. Seasonal variations and epidemiological features in the endemic area of Ambositra. Arch Inst Pasteur Madagascar 45:9-114

Pollak E (1987) On the theory of partially inbreeding finite populations. I. Partial selfing. Genetics 117:353-360

Porcher E, Giraud T, Lavigne C (2006) Genetic differentiation of neutral markers and quantitative traits in predominantly selfing metapopulations: confronting theory and experiments with Arabidopsis thaliana. Genet Res 87:1-12

Pritchard JK, Stephens M, Donnelly P (2000) Inference of population structure using multilocus genotype data. Genetics 155:945-959 
Raso G, Matthys B, N'Goran EK et al (2005) Spatial risk prediction and mapping of Schistosoma mansoni infections among schoolchildren living in western Côte d'Ivoire. Parasitology 131:97-108

Rousset F (2015) Genepop 4.4 for Windows/Linux/Mac OS X

Rowe G, Sweet M, Beebee T (2017) An introduction to molecular ecology, 3rd edn. Oxford University Press

Sire C, Durand P, Pointier JP, Théron A (1999) Genetic diversity and recruitment pattern of Schistosoma mansoni in a Biomphalaria glabrata snail population: a field study using random-amplified polymorphic DNA markers. J parasitol 85:436-441

Städler T, Jarne P (1997) Population biology, genetic structure, and mating system parameters. In Streit B, Städler T, Lively CM (eds) Ecology and evolution of freshwater organisms. Birkhaüser Verlag, Basel, pp 231-262

Stat Soft. (2005) STATISTICA (Data analysis software) 7.1 ed. Paris, France

Théron A. (1986) Polymorphisme des œufs de Schistosoma mansoni dans le foyer Guadeloupéen (Antilles Françaises): présence de «S. rodhaini-like» parasites? Acta trop 43:335-342

Tian-Bi TY-N, N'Goran KE, N'Guetta S-P et al (2008) Prior selfing and the selfing syndrome in animals: an experimental approach in the freshwater snail Biomphalaria pfeifferi. Genet Res 90:61-72

Tian-Bi TY-N, Jarne P, Konan KJ-N et al (2013) Contrasting the distribution of phenotypic and molecular variation in the freshwater snail Biomphalaria pfeifferi, the intermediate host of Schistosoma mansoni. Heredity $110: 466-474$

Trouvé S, Degen L, Renaud F, Goudet J (2003) Evolutionary implications of a high selfing rate in the freshwater snail Lymnaea truncatula. Evolution 57:2303-2314.

Van Leeuwen CH, Huig N, Van Der Velde G et al (2013) How did this snail get here? Several dispersal vectors inferred for an aquatic invasive species. Freshw Biol 58:88-99

Viard F, Justy F, Jarne P (1997) Population dynamics inferred from temporal variation at microsatellite loci in the selfing snail Bulinus truncatus. Genetics 146:973-982

Vucetich JA, Waite TA, Nunney L (1997) Fluctuating population size and the ratio of effective to census population size. Evolution 51:2017-2021

Wang J, Whitlock MC (2003) Estimating effective population size and migration rates from genetic samples over space and time. Genetics 163:429-446

Waples RS (1989) Temporal variation in allele frequencies: testing the right hypothesis. Evolution 43:1236-1251

Weir BS, Cockerham CC (1984) Estimating F-statistics for the analysis of population structure. Evolution $38: 1358-1370$ 
1 Whitehorn PR, Tinsley MC, Brown MJF et al (2011) Genetic diversity, parasite prevalence and immunity in wild bumblebees. Proc R Soc Lond B Biol Sci 278:1195-1202

3 Whitlock MC, McCauley DE (1999) Indirect measures of gene flow and migration: $F_{\mathrm{ST}} \neq 1 /(4 \mathrm{Nm}+1)$. Heredity $4 \quad 82: 117-125$

5 Woolhouse MEJ (1992) Population biology of the freshwater snail Biomphalaria pfeifferi in the Zimbabwe highveld. J ApplEcol 29:687-694

7 Woolhouse MEJ, Chandiwana SK (1989) Spatial and temporal heterogeneity in the population dynamics of Bulinus globosus and Biomphalaria pfeifferi and in the epidemiology of their infection with schistosomes.

9 Parasitology 98:21-34 
Table 1 Information on the seven studied populations of Biomphalaria pfeifferi

\begin{tabular}{|c|c|c|c|c|c|}
\hline Site (acronym) & Coordinates & Type & $\begin{array}{c}\text { Habitat } \\
\text { openness }\end{array}$ & $\begin{array}{l}\text { Habitat } \\
\text { regime }\end{array}$ & $\begin{array}{c}\text { Prevalence } \\
(\%)\end{array}$ \\
\hline Domoraud (DOM) & $07^{\circ} 24^{\prime} \mathrm{N} 07^{\circ} 33^{\prime} \mathrm{W}$ & Irrigation canal & $\mathrm{O}$ & $\mathrm{T}$ & 42 \\
\hline Doyagouiné (DOY) & $07^{\circ} 23^{\prime} \mathrm{N} 07^{\circ} 33^{\prime} \mathrm{W}$ & Rice field (abandoned) & $\mathrm{O}$ & $\mathrm{T}$ & 38 \\
\hline Lycée-Club (LYC) & $07^{\circ} 23^{\prime} \mathrm{N} 07^{\circ} 32^{\prime} \mathrm{W}$ & Irrigation canal & $\mathrm{O}$ & $\mathrm{P}$ & 31 \\
\hline Quartier-Treize (QTT) & $07^{\circ} 24^{\prime} \mathrm{N} 07^{\circ} 32^{\prime} \mathrm{W}$ & Pond & $\mathrm{C}$ & $\mathrm{P}$ & 21 \\
\hline Blolé (BLO) & $07^{\circ} 18^{\prime} \mathrm{N} 07^{\circ} 30^{\prime} \mathrm{W}$ & River & $\mathrm{O}$ & $\mathrm{P}$ & 55.5 \\
\hline Nionlé (NIO) & $07^{\circ} 09^{\prime} \mathrm{N} 07^{\circ} 47^{\prime} \mathrm{W}$ & Rice field & $\mathrm{C}$ & $\mathrm{T}$ & 67 \\
\hline Podiagouiné (POD) & $07^{\circ} 09^{\prime} \mathrm{N} 07^{\circ} 44^{\prime} \mathrm{W}$ & Fish pond & $\mathrm{C}$ & $\mathrm{P}$ & 58.8 \\
\hline
\end{tabular}

O, C, T and P stand for open, closed, temporary and permanent, respectively. Prevalence refers to the prevalence of Schistosoma mansoni in human populations from the study sites 
Table 2 Indicators of demography and genetics in the seven population of B. pfeifferi studied

\begin{tabular}{|c|c|c|c|c|c|c|c|c|c|c|c|c|c|c|}
\hline Population & Sample & $N$ & $N_{h}$ & $\operatorname{Var}(N)$ & $N_{\mathrm{sv}}$ & IP & $N_{\text {an }}$ & $N_{p l}$ & $N_{\text {all }}$ & $H_{O}$ & $H_{E}$ & $\hat{f}$ & $\hat{s}$ & $\hat{s}^{\prime}$ \\
\hline \multirow[t]{5}{*}{ DOM } & DOM-A & 49 & & & 49 & 0.08 & 20 & 4 & $1.80(0.45)$ & $0.00(0.00)$ & $0.24(0.25)$ & 1.00 & 1.00 & 0.92 \\
\hline & DOM-B & 41 & & & 38 & 0.11 & 15 & 2 & $1.40(0.54)$ & $0.01(0.03)$ & $0.08(0.14)$ & 0.84 & 0.91 & - \\
\hline & DOM-C & 54 & & & 40 & 0.00 & 20 & 4 & $1.80(0.45)$ & $0.03(0.04)$ & $0.14(0.11)$ & 0.78 & 0.88 & - \\
\hline & DOM-D & 0 & 3.76 & 580.92 & - & - & - & - & - & - & - & - & - & - \\
\hline & & & & & & 0.06 & & 3.33 & 1.67 & 0.01 & 0.15 & 0.87 & 0.93 & \\
\hline \multirow[t]{5}{*}{ DOY } & DOY-A & 122 & & & 122 & 0.68 & 20 & 3 & $1.60(0.55)$ & $0.07(0.10)$ & $0.15(0.16)$ & 0.82 & 0.90 & 0.94 \\
\hline & DOY-B & 44 & & & 41 & 0.02 & 15 & 2 & $1.40(0.55)$ & $0.00(0.00)$ & $0.10(0.13)$ & 1.00 & 1.00 & - \\
\hline & DOY-C & 29 & & & 27 & 0.00 & 20 & 3 & $1.80(0.84)$ & $0.02(0.03)$ & $0.22(0.25)$ & 0.91 & 0.95 & - \\
\hline & DOY-D & 0 & 3.75 & 2686.0 & - & - & - & - & - & - & - & - & - & \\
\hline & & & & & & 0.23 & & 2.67 & 1.60 & 0.03 & 0.16 & 0.91 & 0.95 & \\
\hline \multirow[t]{5}{*}{ LYC } & LYC-A & 135 & & & 135 & 0.05 & 20 & 1 & $1.20(0.45)$ & $0.00(0.00)$ & $0.02(0.02)$ & 1.00 & 1.00 & - \\
\hline & LYC-B & 94 & & & 71 & 0.04 & 15 & 3 & $1.60(0.55)$ & $0.01(0.03)$ & $0.12(0.17)$ & 0.89 & 0.94 & - \\
\hline & LYC-C & 49 & & & 37 & 0.00 & 20 & 3 & $1.60(0.55)$ & $0.01(0.02)$ & $0.10(0.10)$ & 0.90 & 0.95 & - \\
\hline & LYC-D & 11 & 30.92 & 2900.92 & 11 & 0.00 & 11 & 3 & $1.60(0.55)$ & $0.13(0.18)$ & $0.21(0.21)$ & 0.40 & 0.57 & 0.76 \\
\hline & & & & & & 0.02 & & 2.50 & 1.50 & 0.04 & 0.11 & 0.80 & 0.87 & \\
\hline \multirow[t]{2}{*}{ QTT } & QTT-A & 83 & & & 83 & 0.15 & 20 & 3 & $1.60(0.55)$ & $0.04(0.04)$ & $0.06(0.08)$ & 0.80 & 0.89 & 0.90 \\
\hline & QTT-B & 0 & & & - & - & - & - & - & - & - & - & - & \\
\hline
\end{tabular}




\begin{tabular}{|c|c|c|c|c|c|c|c|c|c|c|c|c|c|c|}
\hline & QTT-C & 43 & & & 39 & 0.00 & 19 & 1 & $1.20(0.45)$ & $0.00(0.00)$ & $0.02(0.05)$ & 1.00 & 1.00 & \\
\hline & QTT-D & 0 & 1.97 & 1548.0 & - & - & - & - & - & - & - & - & - & \\
\hline & & & & & & 0.08 & & 2.00 & 1.40 & 0.02 & 0.04 & 0.90 & 0.95 & \\
\hline \multirow[t]{5}{*}{ BLO } & BLO-A & 21 & & & 21 & 0.00 & 21 & 3 & $1.60(0.55)$ & $0.01(0.02)$ & $0.08(0.08)$ & 0.88 & 0.94 & 0.96 \\
\hline & BLO-B & 24 & & & 18 & 0.00 & 15 & 3 & $1.60(0.55)$ & $0.05(0.12)$ & $0.15(0.17)$ & 0.66 & 0.80 & - \\
\hline & BLO-C & 5 & & & 5 & 0.08 & 4 & 1 & $1.20(0.45)$ & $0.00(0.00)$ & $0.09(0.19)$ & 1.00 & 1.00 & - \\
\hline & BLO-D & 36 & 12.62 & 163 & 33 & 0.09 & 20 & 4 & $2.20(1.10)$ & $0.01(0.02)$ & $0.16(0.11)$ & 0.94 & 0.97 & - \\
\hline & & & & & & 0.04 & & 2.75 & 1.65 & 0.02 & 0.12 & 0.87 & 0.93 & \\
\hline \multirow[t]{5}{*}{ NIO } & NIO-A & 11 & & & 11 & 0.00 & 11 & 1 & $1.20(0.45)$ & $0.02(0.04)$ & $0.07(0.16)$ & 0.76 & 0.86 & - \\
\hline & NIO-B & 79 & & & 49 & 0.00 & 15 & 1 & $1.20(0.45)$ & $0.03(0.06)$ & $0.03(0.06)$ & -0.04 & - & - \\
\hline & NIO-C & 40 & & & 25 & 0.00 & 20 & 3 & $1.80(0.84)$ & $0.02(0.03)$ & $0.08(0.09)$ & 0.75 & 0.86 & - \\
\hline & NIO-D & 1 & 3.54 & 1224.25 & - & - & - & - & - & - & - & - & - & \\
\hline & & & & & & 0.00 & & 1.67 & 1.40 & 0.02 & 0.06 & 0.49 & 0.86 & \\
\hline \multirow[t]{5}{*}{ POD } & POD-A & 7 & & & 7 & 0.00 & 7 & 1 & $1.20(0.45)$ & $0.00(0.00)$ & $0.05(0.12)$ & 1.00 & 1.00 & - \\
\hline & POD-B & 27 & & & 27 & 0.04 & 15 & 3 & $1.60(0.55)$ & $0.03(0.04)$ & $0.17(0.17)$ & 0.86 & 0.92 & 0.98 \\
\hline & POD-C & 16 & & & 10 & 0.00 & 12 & 4 & $1.80(0.84)$ & $0.02(0.04)$ & $0.14(0.11)$ & 0.88 & 0.94 & - \\
\hline & POD-D & 0 & 3.21 & 126.33 & 0 & - & - & - & - & - & - & - & - & \\
\hline & & & & & & 0.01 & & 2.67 & 1.53 & 0.02 & 0.12 & 0.91 & 0.95 & \\
\hline
\end{tabular}

Four temporal samples (A to D) were considered per population. $N, N_{h}$ and $\operatorname{Var}(N)$ are the total number of snails collected, its harmonic mean and variance, respectively. $N_{\mathrm{sv}}$

is the number of surviving snails tested for Schistosoma mansoni prevalence, and IP the infection prevalence. $N_{\text {an }}, N_{p l}, \mathrm{~N}_{a l l}, H_{\mathrm{O}}$ and $H_{\mathrm{E}}$ are the number of individuals used in 
the genetic analysis, the number of polymorphic loci, the mean number of alleles, the mean observed heterozygosity and Nei's unbiased gene diversity over all loci. Standard

errors of genetic parameters are indicated in parentheses. $\hat{f}$ is the estimate of Wright's $F_{\mathrm{IS}}, \hat{s}$ the estimate of the selfing rate derived from $\hat{f}$ and $\hat{s}^{\prime}$ is the estimate of the selfing rate based on the method of David et al. (2007). Values in italics are the arithmetic means of these parameters per population. - means not relevant 
Table 3 Statistical analysis through multiple regression of the effect of demographic and ecological characteristics on genetic parameters

\begin{tabular}{|c|c|c|c|}
\hline & $N_{\text {all }}$ & $H_{E}$ & $\hat{f}$ \\
\hline \multirow{3}{*}{ Whole model } & EMS $=0.25$ & EMS $=0.05$ & EMS $=0.20$ \\
\hline & $F_{3,18}=2.09$ & $F_{3,18}=3.87$ & $F_{3,18}=3.61$ \\
\hline & $P=0.137$ & $P=0.027$ & $P=0.033$ \\
\hline
\end{tabular}

Season

Habitat openness

$0.59(0.013)$

Habitat regime

$N_{h}$

$\operatorname{Var}(N)$

IP

$0.45(0.042)$

$-0.45(0.034)$

Indicators are defined in Table 2. The results on the whole models are given on the first rows. EMS is the error mean square. The regression coefficients of some independent variables are reported together with their associated $p$-values in parentheses. Regression coefficients with $p$-values higher than 0.05 are not shown. After adjustment of $p$-values using the FDR procedure (Benjamini and Hochberg 1995) none of the regression coefficients was significantly different from zero 
Table 4 Estimates of temporal genetic differentiation $\left(F_{S T} ; \hat{\theta}_{t p}\right.$ in text), effective sizes $\left(N_{\mathrm{e}}\right)$ and migration rate $(m)$ between successive samples and over all samples in the seven populations of $B$. pfeifferi

\begin{tabular}{|c|c|c|c|c|c|}
\hline \multirow{2}{*}{ Population } & \multicolumn{4}{|c|}{ Samples } & \multirow{2}{*}{ Over all samples } \\
\hline & & A to $B$ & $\mathrm{~B}$ to $\mathrm{C}$ & $\mathrm{C}$ to $\mathrm{D}$ & \\
\hline \multirow[t]{3}{*}{ DOM } & $F_{S T}$ & 0.27 & 0.71 & - & 0.54 \\
\hline & $N_{\mathrm{e}}$ & $4.1[3.0,7.7]$ & $3.3[2.2,5.2]$ & - & $3.3[2.7,4.3]$ \\
\hline & $m$ & $0.23\left[10^{-4}, 2.0\right]$ & $0.14[0.004,0.42]$ & - & $0.09[0.005,0.35]$ \\
\hline \multirow[t]{3}{*}{ DOY } & $F_{S T}$ & -0.02 & 0.2 & - & 0.14 \\
\hline & $N_{\mathrm{e}}$ & $3.8[2.1,12.0]$ & $5.6[3.0,13.0]$ & - & $4.4[3.0,7.7]$ \\
\hline & $m$ & $0.2[0.01,0.08]$ & $0.2[0.03,0.6]$ & - & $0.3[0.09,0.6]$ \\
\hline \multirow[t]{3}{*}{ LYC } & $F_{S T}$ & 0.15 & 0.61 & 0.09 & 0.57 \\
\hline & $N_{\mathrm{e}}$ & $6.4[3.2,20]$ & $4.0[3.0,6.2]$ & $4.4[3.0,40]$ & $3.5[3.0,4.9]$ \\
\hline & $m$ & $0.3[0.08,0.6]$ & $0.4[0.1,2.0]$ & $0.16\left[10^{-4}, 0.64\right]$ & $0.4[0.18,0.65]$ \\
\hline \multirow[t]{3}{*}{ QTT } & $F_{S T}$ & - & - & - & 0.02 \\
\hline & $N_{\mathrm{e}}$ & - & - & - & $4.3[3.1,6.5]$ \\
\hline & $m$ & - & - & - & $0.19\left[10^{-4}, 0.67\right]$ \\
\hline \multirow[t]{2}{*}{ BLO } & $F_{S T}$ & 0.79 & 0.64 & 0.44 & 0.67 \\
\hline & $N_{\mathrm{e}}$ & $4.0[2.9,5.8]$ & $2.3[1.5,3.9]$ & $8.3[4.4,36]$ & $3.6[3.2,4.7]$ \\
\hline
\end{tabular}




\begin{tabular}{|c|c|c|c|c|c|}
\hline & $m$ & $1.0[0.8,2.0]$ & $7 \times 10^{-5}\left[10^{-5}, 0.4\right]$ & $0.15[0.009,0.38]$ & $0.94[0.7,2.0]$ \\
\hline \multirow[t]{3}{*}{ NIO } & $F_{S T}$ & 0.08 & 0.72 & - & 0.60 \\
\hline & $N_{\mathrm{e}}$ & $2.0[1.8,2.8]$ & $3.4[2.9,5.4]$ & - & $2.5[2.0,3.6]$ \\
\hline & $m$ & $0.9[0.4,2.0]$ & $0.6[0.2,2.0]$ & - & $2 \times 10^{-4}\left[10^{-5}, 0.6\right]$ \\
\hline \multirow[t]{3}{*}{ POD } & $F_{S T}$ & 0.04 & -0.06 & - & -0.02 \\
\hline & $N_{\mathrm{e}}$ & $2.9[1.9,14]$ & $1.5[3.8,1000]$ & - & $2.9[3.4,1000]$ \\
\hline & $m$ & $0.3\left[10^{-4}, 0.8\right]$ & $0.001\left[10^{-5}, 0.25\right]$ & - & $2 \times 10^{-4}\left[10^{-5}, 0.3\right]$ \\
\hline
\end{tabular}

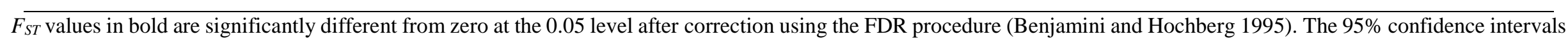
of $N_{\mathrm{e}}$ and $m$ are indicated in brackets. - means not relevant 


\section{Figure captions}

Fig.1 Location of the seven populations of Biomphalaria pfeifferi sampled in the Man area, western Côte d'Ivoire.

The populations sampled in the Man district are indicated in the enlarged panel. Source: Tian-Bi et al. (2013)

Fig.2 Percentage per population of individuals assigned to the population in which they were sampled (white bars) and of individuals excluded (grey bars). Among excluded individuals, individuals reassigned to sampled populations are reported as black bars and individuals not reassigned as gradient filled bars 